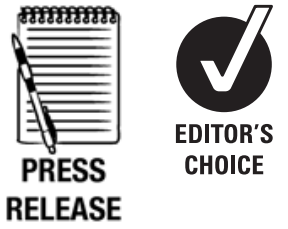

Division of Cancer

Epidemiology, German Cancer Research Centre, Heidelberg.

Germany

Institute of Epidemiology, Helmholtz Centre Munich, Neuherberg, Germany

${ }^{3}$ Division of Cancer

Epidemiology and Prevention, Institute of Social and

Preventive Medicine, University of Zurich, Switzerland

\section{Correspondence to}

Professor Sabine Rohrmann, Division of Cancer Epidemiology and Prevention, Institute of Social and Preventive Medicine, University of Zurich,

Hirschengraben 84, CH-8001

Zurich, Switzerland:

sabine.rohrmann@ifspm.uzh.ch

Accepted 15 February 2012

Published Online First

21 May 2012

\title{
Associations of dietary calcium intake and calcium supplementation with myocardial infarction and stroke risk and overall cardiovascular mortality in the Heidelberg cohort of the European Prospective Investigation into Cancer and Nutrition study (EPIC-Heidelberg)
}

\author{
Kuanrong Li, ${ }^{1}$ Rudolf Kaaks, ${ }^{1}$ Jakob Linseisen, ${ }^{1,2}$ Sabine Rohrmann ${ }^{1,3}$
}

\begin{abstract}
Background It has been suggested that a higher calcium intake might favourably modify cardiovascular risk factors. However, findings of an ultimately decreased risk of cardiovascular disease (CVD) are limited. Instead, recent evidence warns that taking calcium supplements might increase myocardial infarction (MI) risk.

Objective To prospectively evaluate the associations of dietary calcium intake and calcium supplementation with $\mathrm{MI}$ and stroke risk and overall CVD mortality.

Methods Data from 23980 Heidelberg cohort participants of the European Prospective Investigation into Cancer and Nutrition study, aged 35-64 years and free of major CVD events at recruitment, were analysed. Multivariate Cox regression models were used to estimate $\mathrm{HRs}$ and $95 \% \mathrm{Cls.}$
\end{abstract}

Results After an average follow-up time of 11 years, $354 \mathrm{MI}$ and 260 stroke cases and 267 CVD deaths were documented. Compared with the lowest quartile, the third quartile of total dietary and dairy calcium intake had a significantly reduced $\mathrm{Ml}$ risk, with a HR of 0.69 (95\% $\mathrm{Cl} 0.50$ to 0.94$)$ and 0.68 (95\% Cl 0.50 to 0.93$)$, respectively. Associations for stroke risk and CVD mortality were overall null. In comparison with non-users of any supplements, users of calcium supplements had a statistically significantly increased $\mathrm{Ml}$ risk $(\mathrm{HR}=1.86$; 95\% Cl 1.17 to 2.96), which was more pronounced for calcium supplement only users $(\mathrm{HR}=2.39 ; 95 \% \mathrm{Cl} 1.12$ to 5.12 ).

Conclusions Increasing calcium intake from diet might not confer significant cardiovascular benefits, while calcium supplements, which might raise Ml risk, should be taken with caution.

\section{INTRODUCTION}

Epidemiological studies have consistently reported inverse associations between dietary calcium intake and the risk of hypertension, obesity and type 2 diabetes, ${ }^{1-8}$ suggesting that a reasonably higher intake of this mineral might ultimately decrease the occurrence of cardiovascular events. Such a plausible health benefit has indeed been shown by several epidemiological studies. In three prospective studies, dietary calcium intake was significantly inversely associated with the ischaemic stroke risk. $^{9-11}$ A fourth study also found a statistically significant inverse association between dietary calcium intake and mortality from ischaemic heart disease. ${ }^{12}$ In a Swedish male cohort, the association between dietary calcium intake and overall cardiovascular disease (CVD) mortality was inverse and of borderline statistical significance. ${ }^{13}$ However, except for these supportive findings, the majority of observational studies reported null associations. ${ }^{14-21}$

Calcium supplements, which are commonly recommended to elderly people, particularly postmenopausal women, to maintain their bone health, have also been suggested as beneficial agents to improve serum cholesterol profile $e^{22-24}$ and to control hypertension. ${ }^{25}$ However, no strong epidemiological evidence suggests that calcium supplementation might provide cardiovascular benefits. ${ }^{10} \quad 12 \quad 14 \quad 16$ Instead, two recent meta-analyses of clinical trials have prompted a warning that calcium supplements might increase a person's risk of having myocardial infarction (MI). ${ }^{26} 27$

In this study, we aimed to prospectively examine the associations of dietary calcium intake, in total or separated from dairy sources and from non-dairy sources and calcium supplementation with MI and stroke risk and overall CVD mortality in a German cohort.

\section{METHODS}

\section{Study population}

The Heidelberg cohort is one of the two German cohorts participating in the European Prospective Investigation into Cancer and Nutrition (EPIC) study. In 1994-8, the EPIC-Heidelberg cohort recruited 25540 local residents, who were then aged 35-64 years. A detailed description of the recruitment procedures has been published elsewhere. ${ }^{28}$ The ethics committee of the Heidelberg University Medical School approved the study protocol and all participants provided informed consent. In this study, we excluded participants who had a diagnosis of MI, stroke, or transient ischaemic attack at baseline $(n=1322)$. We also excluded participants whose daily energy intake fell into the top or the bottom 0.5 centile (men: <887/>5582 kcal/day; 
women: <70/>4381 kcal/day; $\mathrm{n}=257)$ and eventually 23980 participants remained for analysis.

\section{Assessment of dietary calcium intake and calcium supplementation}

A self-administered food frequency questionnaire (FFO), which had been validated using $1224 \mathrm{~h}$ dietary recalls in a subsample of 104 participants from the two German cohorts, ${ }^{29}{ }^{30}$ was used to assess consumption of 148 food items in the 12 months before the date of recruitment. Dietary calcium intake was derived using the German Nutrient Database BSL, version II.3. Within the entire EPIC-Germany, dairy foods and non-alcoholic beverages were the main sources of dietary calcium, providing 39.9\% and $28.2 \%$ of the daily intake, respectively. ${ }^{31}$ The Spearman correlation coefficient between the FFO and the mean of the 12 24-h dietary recalls was 0.58 for dairy foods and 0.70 for non-alcoholic beverages. ${ }^{30}$

In a baseline interview and follow-up questionnaire surveys, participants were asked if they had regularly taken vitamin/ mineral supplements in the past 4 weeks, where 'regularly' was defined as daily use for at least 1 week or non-daily use of at least five doses on a regular basis. Self-reported supplements were coded using the Anatomical Therapeutic Chemical classification system. Data on dosage were not collected. In this study, we separated cohort participants into users of calcium supplements (Anatomical Therapeutic Chemical code A12A), users of other supplements (containing users of unspecified supplements) and non-users of any supplements. Users of calcium supplements were also separated into calcium supplement only users and users of calcium supplements plus other vitamins/minerals.

\section{Ascertainment of cardiovascular outcomes}

Incident cardiovascular events during follow-up were reported by participants or their next of kin in follow-up surveys. Reported cardiovascular events were verified by tracking medical records or official death certificates. In this study, cardiovascular events of interest, which were coded using the International Classification of Diseases 10th version (ICD-10), were incident MI (ICD-10 codes I21-I23), incident stroke (ICD-10 codes I60-I69) and overall CVD mortality (ICD-10 codes I00-I99).

\section{Statistical analysis}

Dietary intakes of calcium and other nutrients were adjusted for total energy intake of $2200 \mathrm{kcal} /$ day for men and $1700 \mathrm{kcal} /$ day for women using the residual method. ${ }^{32}$ Residuals were obtained from sex-specific linear regressions of the log-transformed calcium intake on the log-transformed total energy intake. The energy-adjusted nutrient intakes were categorised into quartiles using sex-specific cut-off points. The lowest quartiles were used as reference groups.

Age- and sex-adjusted baseline characteristics of participants across quartiles of energy-adjusted total dietary calcium intake and across calcium supplementation status were compared using analysis of covariance for continuous variables and logistic regression for binary variables. ${ }^{33}$ Multivariate Cox regressions were performed to estimate HRs and 95\% CIs. To avoid violation of the proportionality assumption, all models were stratified by the rounded age at recruitment (1-year category). The following potential confounders were adjusted for in the analyses of dietary calcium intake: sex, age at recruitment, the highest educational level (no/primary school, secondary/technical school and university), physical activity (inactive, moderately inactive, moderately active and active), body mass index $\left(\mathrm{BMI}, \mathrm{kg} / \mathrm{m}^{2}\right.$ ), smoking categories (never smoker; former smoker, quit $\geq 10$ years and quit $<10$ years; current smoker, $\leq 10,11-20$ and $>20$ cigarettes/day), lifetime alcohol intake ( $g /$ day), total energy intake (kcal/day), energy-adjusted dietary intakes of vitamin $\mathrm{D}(\mu \mathrm{g} /$ day), saturated fatty acids ( $\mathrm{g} /$ day) and total protein (g/day), self-reported diabetes mellitus at recruitment and use of calcium supplements. Other baseline characteristics, including dietary intakes of fibre, vitamin $\mathrm{C}$ and folic acid, selfreported hypertension, hyperlipidaemia and regular use of antihypertensive drugs, lipid-lowering drugs and non-steroidal anti-inflammatory drugs only slightly affected the HRs and therefore they were not included in the final models. Mutual adjustment for dairy and non-dairy calcium intakes was made when they were analysed separately. Linear trends were examined using the likelihood ratio test, in which the median intakes of quartiles were modelled as a continuous variable.

Multivariate Cox models that examined the effects of calcium supplementation also adjusted for total dietary calcium intake, self-reported hyperlipidaemia and use of non-steroidal antiinflammatory drugs, as they appreciably affected the risk estimates. In addition to examining the effect of calcium supplementation at baseline, extended Cox regression models ${ }^{34}$ were fitted to examine the effects of the most recent and the cumulative calcium supplementation by using the data on supplement use collected during the follow-up. All analyses were repeated after exclusion of CVD events that occurred in the first 2 years of follow-up.

All statistical tests were two-sided, with $\mathrm{p}<0.05$ being considered statistically significant. SAS software (V.9.2; SAS Institute) was used to perform all statistical analyses.

\section{RESULTS}

Table 1 shows the baseline characteristics of participants by quartiles of the energy-adjusted total dietary calcium intake and by calcium supplementation status. A higher dietary calcium intake was mainly associated with favourable factors, including younger age, higher likelihood of having a university degree and being physically active, less likelihood of being overweight/obese (BMI $\geq 25 \mathrm{~kg} / \mathrm{m}^{2}$ ) and current smokers and an average shorter smoking duration and lower lifetime alcohol consumption. Dietary calcium intake was also positively associated with dietary vitamin $\mathrm{D}$, saturated fatty acid and total protein intake and the likelihood of taking calcium supplements. Compared with non-users, users of calcium supplements were more likely to be women, physically more active and less likely to be overweight/obese. On the other hand, users of calcium supplements had an older age, an overall lower educational level and a longer duration of smoking.

After an average follow-up time of 11 years, $354 \mathrm{MI}$ cases, 260 stroke cases and 267 CVD deaths were documented. After adjustment for potential confounders, a statistically significant inverse association was only found between total dietary calcium intake and MI risk for the third quartile compared with the lowest quartile ( $\mathrm{HR}=0.69$; $95 \%$ CI 0.50 to 0.94 ; table 2 ). Compared with the lowest quartile, the second quartile of total calcium intake had a statistically significantly increased stroke risk (1.50; 95\% CI 1.06 to 2.11), which became non-significant after exclusion of the first 2 years of follow-up. For sourcespecific calcium intake, the previously observed reduction of MI risk in the third quartile of total calcium intake remained in the third quartile of dairy calcium intake ( $\mathrm{HR}=0.68 ; 95 \% \mathrm{CI} 0.50$ to 0.93 ; table 3 ). None of the linear trend tests was statistically significant. Further exclusion of supplement users from analyses did not substantially change the risk estimates for total and source-specific dietary calcium intakes (data not shown). 
Table 1 Age- and sex-adjusted baseline characteristics of participants by sex-specific quartile of dietary calcium intake and calcium supplementation status, the EPIC-Heidelberg cohort, 1994-1998

\begin{tabular}{|c|c|c|c|c|c|c|c|}
\hline \multirow[b]{2}{*}{ Characteristics } & \multicolumn{4}{|c|}{ Total dietary calcium intake in quartiles* } & \multicolumn{3}{|c|}{ Calcium supplementation } \\
\hline & 1 (low) & 2 & 3 & 4 (high) & $\begin{array}{l}\text { Calcium } \\
\text { supplements }\end{array}$ & $\begin{array}{l}\text { Other } \\
\text { supplements }\end{array}$ & $\begin{array}{l}\text { No supplements } \\
\text { used }\end{array}$ \\
\hline No of participants $†$ & 5986 & 5993 & 5998 & 6003 & 851 & 7170 & 15959 \\
\hline Total dietary calcium intake* $(\mathrm{mg} /$ day) & 513 & 675 & 820 & $1130 \ddagger$ & 828 & 820 & $766 \ddagger$ \\
\hline Dairy calcium intake* (mg/day) & 188 & 330 & 466 & $780 \ddagger$ & 477 & 470 & $426 \ddagger$ \\
\hline Non-dairy calcium intake* (mg/day) & 324 & 345 & 353 & $351 \neq$ & 352 & 349 & $340 \ddagger$ \\
\hline Dietary vitamin $D$ intake* ${ }^{*} \mu \mathrm{g} /$ day) & 3.0 & 3.2 & 3.3 & $3.4 \ddagger$ & 3.4 & 3.4 & $3.2 \ddagger$ \\
\hline Dietary intake of saturated fatty acids* $(\mathrm{g} /$ day $)$ & 30.0 & 30.8 & 31.3 & $32.3 \ddagger$ & 30.6 & 30.7 & $31.3 \neq$ \\
\hline Dietary intake of total protein* $(\mathrm{g} /$ day) & 65.2 & 67.3 & 69.5 & $74.5 \ddagger$ & 70.3 & 69.2 & 69.0 \\
\hline Smoking duration (years) & 13.5 & 11.8 & 11.5 & $11.7 \ddagger$ & 13.0 & 12.3 & $12.0 \neq$ \\
\hline Lifetime alcohol intake (g/day) & 21.3 & 17.7 & 15.2 & $13.8 \ddagger$ & 17.3 & 17.1 & 17.0 \\
\hline Age at recruitment (years) & 51.2 & 50.6 & 50.3 & $50.5 \ddagger$ & 53.6 & 51.8 & $50.0 \neq$ \\
\hline Women (\%) & 54.1 & 54.0 & 54.2 & 54.0 & 72.4 & 60.9 & $49.8 \neq$ \\
\hline University degree (\%) & 21.5 & 28.6 & 33.2 & $38.1 \neq$ & 25.2 & 33.8 & $29.1 \neq$ \\
\hline Physically active (\%) & 22.0 & 24.1 & 24.2 & $29.3 \ddagger$ & 32.7 & 25.6 & $24.2 \ddagger$ \\
\hline $\mathrm{BMI} \geq 25 \mathrm{~kg} / \mathrm{m}^{2}(\%)$ & 57.8 & 56.9 & 54.9 & $53.1 \neq$ & 50.9 & 51.8 & $57.6 \neq$ \\
\hline Current smokers (\%) & 28.8 & 22.1 & 20.9 & $21.5 \ddagger$ & 23.9 & 22.1 & $23.9 \neq$ \\
\hline Hypertension at recruitment§ (\%) & 29.2 & 29.1 & 27.8 & 28.2 & 26.7 & 28.9 & 28.6 \\
\hline Hyperlipidaemia at recruitment $\S(\%)$ & 35.6 & 36.7 & 34.5 & 35.0 & 38.8 & 37.0 & $34.6 \neq$ \\
\hline Diabetes mellitus at recruitment $\S(\%)$ & 3.1 & 3.5 & 3.4 & $4.8 \ddagger$ & 3.5 & 3.5 & 3.8 \\
\hline Use of anti-hypertensive drugs (\%) & 13.6 & 14.7 & 13.5 & 14.3 & 13.8 & 16.3 & $13.0 \neq$ \\
\hline Use of lipid-lowering drugs (\%) & 3.3 & 3.7 & 4.0 & 3.9 & 4.9 & 4.4 & $3.3 \neq$ \\
\hline Use of NSAIDs (\%) & 6.0 & 5.5 & 5.7 & 6.5 & 9.6 & 8.0 & $4.8 \neq$ \\
\hline Use of calcium supplements (\%) & 3.1 & 3.2 & 3.5 & $4.4 \ddagger$ & & & \\
\hline
\end{tabular}

*Adjusted for total energy intake using the residual method. The cut-off points were 603,748 and $924 \mathrm{mg} /$ day for men and 610,738 and $898 \mathrm{mg} /$ day for women.

†Participants with a diagnosis of myocardial infarction, stroke, or transient ischaemic attack at recruitment and participants whose total energy intake fell into the top or bottom 0.5 sex-specific centile (men: <887/>5582 kcal/day; women: $<703 />4381 \mathrm{kcal} /$ day) were excluded.

$\neq \mathrm{p}<0.05$. Values are either percentages or means.

$\S$ Self-reported.

BMI, body mass index; EPIC, European Prospective Investigation into Cancer and Nutrition; NSAIDS, non-steroidal anti-inflammatory drugs

As shown in table 4, users of calcium supplements had a statistically significantly increased MI risk in comparison with non-users of any supplements ( $\mathrm{HR}=1.86$; $95 \%$ CI 1.17 to 2.96$)$. This association was more pronounced for calcium supplement

Table 2 Multivariate HRs and 95\% Cls for $\mathrm{Ml}$ and stroke incidence and CVD mortality by quartile of total dietary calcium intake, the EPICHeidelberg cohort, 1994-2010

\begin{tabular}{|c|c|c|c|c|}
\hline & \multirow[b]{2}{*}{ Quartile } & \multirow{2}{*}{$\begin{array}{l}\text { No of } \\
\text { cases }\end{array}$} & \multicolumn{2}{|l|}{ HR and $95 \% \mathrm{CI}$} \\
\hline & & & Model A & Model B \\
\hline \multirow[t]{5}{*}{ MI incidence } & 1 (low) & 101 & 1.00 (ref) & 1.00 (ref) \\
\hline & 2 & 91 & $0.94(0.70$ to 1.25$)$ & $1.01(0.75$ to 1.37$)$ \\
\hline & 3 & 70 & $0.69(0.50$ to 0.94$)$ & $0.67(0.48$ to 0.94$)$ \\
\hline & 4 (high) & 92 & 0.85 (0.63 to 1.16$)$ & $0.92(0.66$ to 1.27$)$ \\
\hline & $\mathrm{p}_{\text {trend }}$ & & 0.22 & 0.39 \\
\hline \multirow[t]{5}{*}{ Stroke incidence } & 1 (low) & 58 & 1.00 (ref) & 1.00 (ref) \\
\hline & 2 & 79 & 1.50 (1.06 to 2.11$)$ & $1.38(0.94$ to 2.01$)$ \\
\hline & 3 & 64 & 1.24 (0.86 to 1.79$)$ & $1.28(0.86$ to 1.89$)$ \\
\hline & 4 (high) & 59 & $1.12(0.76$ to 1.65$)$ & $1.17(0.77$ to 1.77$)$ \\
\hline & $\mathrm{p}_{\text {trend }}$ & & 0.97 & 0.73 \\
\hline \multirow[t]{5}{*}{ CVD mortality } & 1 (low) & 65 & 1.00 (ref) & 1.00 (ref) \\
\hline & 2 & 75 & 1.34 (0.95 to 1.88$)$ & $1.51(1.05$ to 2.17$)$ \\
\hline & 3 & 61 & $1.15(0.80$ to 1.65$)$ & $1.22(0.83$ to 1.81$)$ \\
\hline & 4 (high) & 66 & $1.18(0.82$ to 1.72$)$ & $1.30(0.87$ to 1.94$)$ \\
\hline & $\mathrm{p}_{\text {trend }}$ & & 0.62 & 0.44 \\
\hline
\end{tabular}

Model A: adjusted for sex, age at recruitment, educational level, physical activity, BMI, smoking categories, lifetime alcohol intake, energy-adjusted dietary vitamin $D$, saturated fatty acid and total protein intake, total energy intake, self-reported diabetes mellitus at recruitment and use of calcium supplements.

Model B: cardiovascular events that occurred in the first 2 years of follow-up were excluded.

BMI, body mass index; CVD, cardiovascular disease; EPIC, European Prospective Investigation into Cancer and Nutrition; MI, myocardial infarction. only users ( $\mathrm{HR}=2.39 ; 95 \% \mathrm{CI} 1.12$ to 5.12$)$ and persisted after MI cases that occurred in the first 2 years of follow-up were excluded ( $\mathrm{HR}=2.70 ; 95 \% \mathrm{CI} 1.26$ to 5.79$)$. As shown in the extended Cox regression models, the most recent but not the cumulative calcium only supplementation was significantly positively associated with MI risk ( $\mathrm{HR}=2.17$; 95\% CI 1.06 to 4.42). No statistically significant association was found between calcium supplementation and either stroke risk or overall CVD mortality.

\section{DISCUSSION}

In this prospective cohort study, total, dairy, or non-dairy calcium intake did not have an overall statistically significant inverse association with cardiovascular risk, except for a likely reduction of MI risk associated with a moderately higher dairy calcium intake. However, this study also suggests that MI risk might be substantially increased by taking calcium supplements.

The association between dietary calcium intake and MI risk has been rarely reported. In our cohort, a moderately higher dietary calcium intake (the third quartile, mean $=820 \mathrm{mg} /$ day) was statistically significantly associated with a $30 \%$ lower MI risk. However, this inverse association became non-significant for men ( $\mathrm{HR}=0.80 ; 95 \% \mathrm{CI} 0.56$ to 1.14$)$ but more significant for women $(\mathrm{HR}=0.43 ; 95 \% \mathrm{CI} 0.22$ to 0.82$)$. A possible explanation for this gender-related disparity might be, if we assume that the observed inverse association was false, that a higher dietary calcium intake was associated with certain uncontrolled confounders in women but not in men. In a cohort study of middle-aged and elderly US male health professionals, which has perhaps been the only large-scale study reporting this association so far, no significant results were found, even in participants 
Table 3 Multivariate $\mathrm{HRs}$ and $95 \% \mathrm{Cls}$ for $\mathrm{Ml}$ and stroke incidence and CVD mortality by quartile of dairy and non-dairy calcium intake, the EPICHeidelberg cohort, 1994-2010

\begin{tabular}{|c|c|c|c|c|}
\hline & \multirow[b]{2}{*}{ Quartile* } & \multirow{2}{*}{$\begin{array}{l}\text { No of } \\
\text { cases }\end{array}$} & \multicolumn{2}{|l|}{$\mathrm{HR}$ and $95 \% \mathrm{Cl}$} \\
\hline & & & Model A & Model B \\
\hline \multicolumn{5}{|l|}{ Dairy calcium } \\
\hline \multirow[t]{5}{*}{ MI incidence } & 1 (low) & 104 & 1.00 (ref) & 1.00 (ref) \\
\hline & 2 & 91 & 0.91 (0.68 to 1.21$)$ & $0.89(0.66$ to 1.20$)$ \\
\hline & 3 & 71 & $0.68(0.50$ to 0.93$)$ & $0.64(0.46$ to 0.90$)$ \\
\hline & 4 (high) & 88 & $0.77(0.57$ to 1.05$)$ & 0.77 (0.56 to 1.07$)$ \\
\hline & $\mathrm{p}_{\text {trend }}$ & & 0.07 & 0.10 \\
\hline \multirow[t]{5}{*}{ Stroke incidence } & 1 (low) & 71 & 1.00 (ref) & 1.00 (ref) \\
\hline & 2 & 66 & $1.01(0.72$ to 1.42$)$ & $0.97(0.67$ to 1.40$)$ \\
\hline & 3 & 58 & 0.91 (0.64 to 1.31 ) & $0.88(0.60$ to 1.31$)$ \\
\hline & 4 (high) & 65 & $1.01(0.70$ to 1.47$)$ & $1.04(0.70$ to 1.55$)$ \\
\hline & $\mathrm{p}_{\text {trend }}$ & & 0.91 & 0.90 \\
\hline \multirow[t]{5}{*}{ CVD mortality } & 1 (low) & 70 & 1.00 (ref) & 1.00 (ref) \\
\hline & 2 & 65 & $1.07(0.76$ to 1.50$)$ & $1.17(0.81$ to 1.69$)$ \\
\hline & 3 & 63 & $1.07(0.76$ to 1.53$)$ & $1.15(0.78$ to 1.67$)$ \\
\hline & 4 (high) & 69 & 1.09 (0.76 to 1.58$)$ & $1.16(0.78$ to 1.72$)$ \\
\hline & Ptrend & & 0.70 & 0.56 \\
\hline \multicolumn{5}{|l|}{ Non-dairy calcium } \\
\hline \multirow[t]{5}{*}{ MI incidence } & 1 (low) & 98 & 1.00 (ref) & 1.00 (ref) \\
\hline & 2 & 84 & $0.93(0.69$ to 1.25$)$ & 0.94 (0.68 to 1.28 ) \\
\hline & 3 & 73 & 0.85 (0.62 to 1.16$)$ & $0.82(0.59$ to 1.15$)$ \\
\hline & 4 (high) & 99 & $1.15(0.86$ to 1.55$)$ & 1.22 (0.90 to 1.67$)$ \\
\hline & $\mathrm{p}_{\text {trend }}$ & & 0.40 & 0.24 \\
\hline \multirow[t]{5}{*}{ Stroke incidence } & 1 (low) & 68 & 1.00 (ref) & 1.00 (ref) \\
\hline & 2 & 53 & $0.84(0.58$ to 1.20$)$ & 0.91 (0.62 to 1.35$)$ \\
\hline & 3 & 61 & $0.99(0.70$ to 1.42$)$ & 1.01 (0.68 to 1.49$)$ \\
\hline & 4 (high) & 78 & 1.26 (0.89 to 1.77$)$ & 1.35 (0.93 to 1.95$)$ \\
\hline & $\mathrm{p}_{\text {trend }}$ & & 0.08 & 0.07 \\
\hline \multirow[t]{5}{*}{ CVD mortality } & 1 (low) & 87 & 1.00 (ref) & 1.00 (ref) \\
\hline & 2 & 59 & 0.77 (0.55 to 1.08 ) & $0.73(0.51$ to 1.05$)$ \\
\hline & 3 & 58 & 0.80 (0.57 to 1.13$)$ & $0.82(0.57$ to 1.17$)$ \\
\hline & 4 (high) & 63 & 0.89 (0.63 to 1.25$)$ & $0.81(0.56$ to 1.17$)$ \\
\hline & $\mathrm{p}_{\text {trend }}$ & & 0.53 & 0.32 \\
\hline
\end{tabular}

Model A: adjusted for sex, age at recruitment, educational level, physical activity, BMI, smoking categories, lifetime alcohol intake, energy-adjusted dietary vitamin D, saturated fatty acid and total protein intake, total energy intake, self-reported diabetes mellitus at recruitment and use of calcium supplements. Dairy calcium intake and non-dairy calcium intake were also mutually adjusted for.

Model B: cardiovascular events that occurred in the first 2 years of follow-up were excluded.

*For dairy calcium intake, the cut-off points were 236, 372 and $552 \mathrm{mg} /$ day for men and 283,410 and $572 \mathrm{mg} /$ day for women. For non-dairy calcium intake, the cut-off points were 319,359 and $404 \mathrm{mg} /$ day for men and 280, 316 and $357 \mathrm{mg} /$ day for women.

$\mathrm{BMI}$, body mass index; CVD, cardiovascular disease; EPIC, European Prospective Investigation into Cancer and Nutrition; MI, myocardial infarction.

who had similar calcium intakes for which the association was statistically significant in this study. ${ }^{14}$ In our cohort, the inverse association was only confined to dairy calcium intake, suggesting a possibility that the inverse association might be caused by other unknown nutrients coexisting in milk products. For instance, three case-control studies have reported an inverse association between dairy fat biomarkers (pentadecanoic and heptadecanoic acid) and the risk of a first-ever MI or cardiovascular risk factors. ${ }^{35-37}$

Our finding of an overall null association between total, dairy, or non-dairy calcium intake and stroke risk is consistent with the majority of previous findings, ${ }^{15-17} 21$ although two studies of Japanese/Japanese immigrants and one study of US women observed a statistically significant inverse association. ${ }^{9-11}$ An easy interpretation of this inverse association is that the potential anti-hypertensive effect of calcium might cause an ultimate reduction in ischaemic stroke risk. However, none of these three studies reported a similar reduced risk of haemorrhagic stroke, which is equally likely to be caused by hypertension. In addition, the much lower dietary calcium intake in two Japanese studies limits its comparability with results from a Western population. A meta-analysis found that a higher consumption of milk, a major dietary source of calcium in Western countries, was statistically significantly associated with a decreased risk of ischaemic stroke. ${ }^{38}$ However, it is hard to conclude that this inverse association is mainly driven by the calcium content.

In this study, no overall statistically significant association was found between total, dairy, or non-dairy calcium intake and CVD mortality. This finding is in line with two other studies. ${ }^{18} 20$ In a third study of Swedish men, the association was almost statistically significant (HR highest vs lowest tertile: $0.77 ; 95 \%$ CI 0.58 to $\left.1.01 ; p_{\text {trend }}=0.06\right) .{ }^{13}$ In comparison with the studies reporting null associations, including this study, the Swedish study had a significantly higher dietary calcium intake (overall mean $=1400 \mathrm{mg} / \mathrm{day}$; mean for the highest tertile $=1953 \mathrm{mg} /$ day). The effect of dietary calcium intake at such a high level on CVD mortality, however, might not be possible for many observational studies to investigate.

We observed a statistically significantly increased MI risk among users of calcium supplements, in agreement with the results of two meta-analyses of clinical trials. ${ }^{26} 27$ The more pronounced increase was seen among calcium supplement only users, suggesting that this adverse effect is mainly from calcium supplements themselves. Unlike the baseline and the most recent calcium supplementation, the model for cumulative calcium supplementation only yielded a statistically nonsignificant inverse association with MI risk. However, it should be noted that this model was based on a hypothetical linear relationship between times of self-reported calcium supplementation and MI risk. Therefore, we conclude that for an elderly population, this adverse effect might not rely much on a very long-term of supplementation. So far, only a few observational studies have reported the association between calcium supplementation and MI risk. In the US study of male health professionals, this association was null. ${ }^{14}$ In a small British cohort study of women, calcium plus vitamin $\mathrm{D}$ supplementation was also not associated with MI risk. ${ }^{39}$ There has been one study that observed an increased risk of coronary heart disease among women who took calcium or calcium plus vitamin D supplements. ${ }^{40}$ To the best of our knowledge, this study is the first observational study to report a possible adverse effect of calcium supplements on MI risk. With respect to the associations between calcium supplementation and stroke risk and overall CVD mortality, this study and all previous observational studies are in agreement on the null associations. ${ }^{10} 121416$

The underlying mechanisms of the adverse effect of calcium supplements on MI risk might be related to the acute increase in serum calcium, which has been observed after ingestion of calcium supplements, but not after eating calcium-rich foods. ${ }^{41}{ }^{42}$ Several studies have observed a positive association between serum calcium levels and vascular calcification. ${ }^{43} 44$ Too much calcium in serum might cause this pathological change by influencing calcification modulators such as pyrophosphate and binding to the calcium-sensing receptors on vascular smooth muscle cells. ${ }^{45}$ Other studies have reported positive associations of serum calcium levels with some predictive biomarkers of CVD, such as fasting insulin and lipid measures, ${ }^{46} 47$ and more directly, with MI risk. ${ }^{48-50}$ As a key regulator of calcium metabolism, parathyroid hormone has also shown a close relationship with cardiovascular risk. ${ }^{51-53}$ Therefore, in order to 
Table 4 Multivariate HRs and 95\% Cls for MI and stroke incidence and CVD mortality by calcium supplementation status, the EPIC-Heidelberg cohort, 1994-2010

\begin{tabular}{|c|c|c|c|c|c|c|}
\hline & \multirow[b]{2}{*}{ Supplements } & \multirow[b]{2}{*}{ No of cases } & \multicolumn{4}{|l|}{$\mathrm{HR}$ and $95 \% \mathrm{Cl}$} \\
\hline & & & Model A & Model B & Model C & Model D \\
\hline \multirow[t]{4}{*}{ Ml incidence } & Non-use of any supplements & 256 & 1.00 (ref) & 1.00 (ref) & 1.00 (ref) & 1.00 (ref) \\
\hline & Calcium & 20 & $1.86(1.17$ to 2.96$)$ & 1.79 (1.09 to 2.96$)$ & $1.28(0.89$ to 1.85$)$ & $1.20(0.93$ to 1.54$)$ \\
\hline & Calcium plus others $\dagger$ & 13 & $1.66(0.95$ to 2.93$)$ & $1.45(0.77$ to 2.75$)$ & 1.14 (0.76 to 1.72$)$ & $1.16(0.88$ to 1.52$)$ \\
\hline & Other supplements & 78 & $0.75(0.58$ to 0.97$)$ & $0.75(0.57$ to 0.99$)$ & 0.86 (0.67 to 1.12$)$ & $0.86(0.72$ to 1.01$)$ \\
\hline \multirow[t]{3}{*}{ Stroke incidence } & Non-use of any supplements & 179 & 1.00 (ref) & 1.00 (ref) & 1.00 (ref) & 1.00 (ref) \\
\hline & Calcium plus others $\dagger$ & 9 & 1.35 (0.69 to 2.66$)$ & 1.31 (0.61 to 2.82 ) & $1.17(0.74$ to 1.86$)$ & $1.00(0.70$ to 1.43$)$ \\
\hline & Others & 71 & $0.87(0.66$ to 1.16$)$ & $0.97(0.71$ to 1.31$)$ & $0.86(0.64$ to 1.15$)$ & 0.89 (0.74 to 1.09$)$ \\
\hline \multirow[t]{3}{*}{ CVD mortality } & Non-use of any supplements & 184 & 1.00 (ref) & 1.00 (ref) & 1.00 (ref) & 1.00 (ref) \\
\hline & Calcium & 9 & $1.02(0.51$ to 2.00$)$ & $1.04(0.51$ to 2.15$)$ & $1.14(0.76$ to 1.72$)$ & $1.07(0.82$ to 1.41$)$ \\
\hline & Calcium only* & 3 & $1.20(0.38$ to 3.78$)$ & 1.39 (0.44 to 4.39$)$ & 1.54 (0.63 to 3.78$)$ & $1.23(0.63$ to 2.40$)$ \\
\hline
\end{tabular}

Model A: adjusted for sex, age at recruitment, educational level, physical activity, BMI, smoking categories, lifetime alcohol intake, energy-adjusted total dietary calcium, vitamin D, saturated fatty acid and total protein intake, total energy intake and self-reported hyperlipidaemia and diabetes mellitus at recruitment and use of NSAIDs.

Model B: excluded cardiovascular events that occurred in the first 2 years of follow-up.

Model C: the effects of the most recent supplementation.

Model D: the effects of the cumulative supplementation. The HRs indicate the relative risks for each self-report of supplementation.

${ }^{*} \mathrm{n}=256$.

$+\mathrm{n}=695$.

BMI, body mass index; CVD, cardiovascular disease; EPIC, European Prospective Investigation into Cancer and Nutrition; MI, myocardial infarction; NSAIDS, non-steroidal anti-inflammatory drugs.

achieve a better understanding of the mechanisms behind the adverse cardiovascular effect of calcium supplementation, its interactions with of parathyroid hormone should be investigated.

Our study has several strengths, such as its prospective design, relatively large sample size and an average follow-up time of more than 10 years. However, this study also has several important limitations.

First, our dietary data contained measurement errors, which are unavoidable in application of a FFO. In addition, one single measure of dietary nutrient intakes at baseline apparently could not capture the long-term variation, as we know that individuals might modify their diet after onset of certain diseases or enhancement of health consciousness. The same problem also stands for those modifiable lifestyle confounders.

Second, this study only excluded pre-existing MI, stroke and transient ischaemic attack. Failing to exclude individuals with other pre-existing CVD subtypes might attenuate an inverse association with CVD mortality if they were more likely to have a calcium-rich diet than relatively healthy individuals, or the other way round. However, the influence of this incomplete exclusion should be minor, as MI and stroke together account for the vast majority of CVD. There is also no evidence suggesting that individuals with pre-MI conditions are more likely to take calcium supplements. On the contrary, the positive association between calcium supplementation and MI risk was strengthened by exclusion of the first 2-year follow-up.

Third, in most of the clinical trials included in the abovementioned meta-analyses, ${ }^{26} 27$ calcium in elemental form was administered at $\geq 1000 \mathrm{mg} /$ day. Therefore, whether a lower dosage will still pose an extra MI risk should be examined. Unfortunately, this study could not answer this question owing to lack of detailed data.

Lastly, it needs to be noted that $44.5 \%$ of vitamin/mineral users in this study did not report the names of their supplements and we therefore only identified a limited number of calcium supplement users, who accounted for $3.6 \%$ of all cohort participants. This prevalence is lower than that observed in a small German elderly population (about $8 \%$ in men and $27 \%$ in women). ${ }^{54}$ It is also lower than the prevalence (11.0\%) reported by a US national survey. ${ }^{55}$ It is possible that the unreported calcium supplementation would affect the accuracy of our results if identified calcium supplement users had a different cardiovascular risk profile than unidentified calcium supplement users.

In conclusion, this study suggests that increasing dietary calcium intake from diet might not confer significant cardiovascular benefits, while calcium supplements, which might raise MI risk, should be taken with caution.

Acknowledgements The authors thank all cohort participants for their consistent participation. We are also grateful to our colleagues, Marie-Luise Groß, Jutta Schmitt and Dorothee Zoller, for their work in disease verification and data preparation.

Contributors KL: data analysis, result interpretation and manuscript writing. JL, RK and SR: reviewed and commented on the manuscript. RK: administrative and financia support.

Funding This work was supported by supported by the Deutsche Krebshilfe (grant-No 70-488-Ha I) and the Graduiertenkolleg 793: Epidemiology of communicable and chronic non-communicable disease and their inter-relationships.

\section{Competing interests None.}

Patient consent Obtained.

Ethics approval Ethics approval was provided by the ethics committee of the Heidelberg University Medical School.

Provenance and peer review Not commissioned; internally peer reviewed.

\section{REFERENCES}

1. Allender PS, Cutler JA, Follmann D, et al. Dietary calcium and blood pressure: a meta-analysis of randomized clinical trials. Ann Intern Med 1996;124:825-31.

2. Bucher HC, Cook RJ, Guyatt GH, et al. Effects of dietary calcium supplementation on blood pressure. A meta-analysis of randomized controlled trials. JAMA 1996;275:1016-22.

3. Cappuccio FP, Elliott P, Allender PS, et al. Epidemiologic association between dietary calcium intake and blood pressure: a meta-analysis of published data. Am J Epidemiol 1995;142:935-45 
4. Villegas R, Gao YT, Dai 0, et al. Dietary calcium and magnesium intakes and the risk of type 2 diabetes: the Shanghai Women's Health Study. Am J Clin Nutr 2009;89:1059-67.

5. Teegarden D. Calcium intake and reduction in weight or fat mass. J Nutr 2003;133:249S-51S

6. Dicker D, Belnic $Y$, Goldsmith $R$, et al. Relationship between dietary calcium intake, body mass index and waist circumference in MABAT-the Israeli National Health and Nutrition Study. Isr Med Assoc J 2008;10:512-15.

7. Garcia-Lorda P, Salas-Salvado J, Fernandez BJ, et al. Dietary calcium and body mass index in a Mediterranean population. Int J Vitam Nutr Res 2007;77:34-40.

8. Zemel MB, Shi H, Greer B, et al. Regulation of adiposity by dietary calcium. FASEB J 2000;14:1132-8.

9. Umesawa M, Iso $\mathrm{H}$, Ishihara J, et al. Dietary calcium intake and risks of stroke, its subtypes and coronary heart disease in Japanese: the JPHC Study Cohort I. Stroke 2008:39:2449-56.

10. Iso H, Stampfer MJ, Manson JE, et al. Prospective study of calcium, potassium and magnesium intake and risk of stroke in women. Stroke 1999:30:1772-9.

11. Abbott RD, Curb JD, Rodriguez BL, et al. Effect of dietary calcium and milk consumption on risk of thromboembolic stroke in older middle-aged men. The Honolulu Heart Program. Stroke 1996:27:813-18.

12. Bostick RM, Kushi LH, Wu Y, et al. Relation of calcium, vitamin D and dairy food intake to ischemic heart disease mortality among postmenopausal women. Am J Epidemiol 1999:149:151-61.

13. Kaluza J, Orsini N, Levitan EB, et al. Dietary calcium and magnesium intake and mortality: a prospective study of men. Am J Epidemiol 2010;171:801-7.

14. Al-Delaimy WK, Rimm E, Willett WC, et al. A prospective study of calcium intake from diet and supplements and risk of ischemic heart disease among men. Am J Clin Nutr 2003:77:814-18.

15. Marniemi J, Alanen E, Impivaara 0, et al. Dietary and serum vitamins and minerals as predictors of myocardial infarction and stroke in elderly subjects. Nutr Metab Cardiovasc Dis 2005:15:188-97.

16. Ascherio A, Rimm EB, Hernan MA, et al. Intake of potassium, magnesium, calcium and fiber and risk of stroke among US men. Circulation 1998;98:1198-204.

17. Larsson SC, Virtanen MJ, Mars M, et al. Magnesium, calcium, potassium and sodium intakes and risk of stroke in male smokers. Arch Intern Med 2008;168:459-65.

18. Umesawa $\mathbf{M}$, Iso $\mathrm{H}$, Date $\mathrm{C}$, et al. Dietary intake of calcium in relation to mortality from cardiovascular disease: the JACC Study. Stroke 2006;37:20-6.

19. Ross RK, Yuan JM, Henderson BE, et al. Prospective evaluation of dietary and other predictors of fatal stroke in Shanghai, China. Circulation 1997;96:50-5.

20. Van der Vijver LP, van der Waal MA, Weterings KG, et al. Calcium intake and 28year cardiovascular and coronary heart disease mortality in Dutch civil servants. Int $\mathrm{J}$ Epidemiol 1992;21:36-9.

21. Larsson SC, Virtamo J, Wolk A. Potassium, calcium and magnesium intakes and risk of stroke in women. Am J Epidemiol 2011;174:35-43.

22. Reid IR, Mason B, Horne A, et al. Effects of calcium supplementation on serum lipid concentrations in normal older women: a randomized controlled trial. Am J Med 2002;112:343-7.

23. Major GC, Alarie F, Dore J, et al. Supplementation with calcium + vitamin D enhances the beneficial effect of weight loss on plasma lipid and lipoprotein concentrations. Am J Clin Nutr 2007;85:54-9.

24. Ditscheid B, Keller S, Jahreis G. Cholesterol metabolism is affected by calcium phosphate supplementation in humans. J Nutr 2005:135:1678-82.

25. van Mierlo LA, Arends LR, Streppel MT, et al. Blood pressure response to calcium supplementation: a meta-analysis of randomized controlled trials. J Hum Hypertens 2006:20:571-80.

26. Bolland MJ, Grey A, Gamble GD, et al. Calcium and vitamin D supplements and health outcomes: a reanalysis of the Women's Health Initiative (WHI) limited-access data set. Am J Clin Nutr 2011;94:1144-9.

27. Bolland MJ, Avenell A, Baron JA, et al. Effect of calcium supplements on risk of myocardial infarction and cardiovascular events: meta-analysis. BMJ 2010:341:c3691.

28. Boeing H, Wahrendorf J, Becker N. EPIC-Germany-A source for studies into diet and risk of chronic diseases. European Investigation into Cancer and Nutrition. Ann Nutr Metab 1999;43:195-204.

29. Bohlscheid-Thomas S, Hoting I, Boeing $\mathrm{H}$, et al. Reproducibility and relative validity of energy and macronutrient intake of a food frequency questionnaire developed for the German part of the EPIC project. European Prospective Investigation into Cancer and Nutrition. Int J Epidemiol 1997;26(Suppl 1):S71-81.

30. Bohlscheid-Thomas S, Hoting I, Boeing H, et al. Reproducibility and relative validity of food group intake in a food frequency questionnaire developed for the German part of the EPIC project. European Prospective Investigation into Cancer and Nutrition. Int $J$ Epidemiol 1997;26(Suppl 1):S59-70.

31. Welch AA, Fransen $\mathrm{H}$, Jenab $\mathrm{M}$, et al. Variation in intakes of calcium, phosphorus magnesium, iron and potassium in 10 countries in the European Prospective Investigation into Cancer and Nutrition study. Eur J Clin Nutr 2009;63(Suppl 4): S101-21.

32. Willett W, Stampfer MJ. Total energy intake: implications for epidemiologic analyses. Am J Epidemiol 1986;124:17-27.

33. Zhao D. Logistic regression adjustment of proportion and its macro procedure http://www2.sas.com/proceedings/sugi22/POSTERS/PAPER227.PDF laccessed 1 Feb 2012).

34. Allison PD. Survival Analysis Using SAS: a Practical Guide. North Carolina, USA SAS publishing, 1995:138-54.

35. Warensjo $\mathbf{E}$, Jansson $\mathrm{JH}$, Cederholm $\mathrm{T}$, et al. Biomarkers of milk fat and the risk of myocardial infarction in men and women: a prospective, matched case-control study. Am J Clin Nutr 2010;92:194-202.

36. Biong AS, Veierod MB, Ringstad J, et al. Intake of milk fat, reflected in adipose tissue fatty acids and risk of myocardial infarction: a case-control study. Eur J Clin Nutr 2006;60:236-44

37. Warensio $\mathbf{E}$, Jansson $\mathrm{JH}$, Berglund $\mathrm{L}$, et al. Estimated intake of milk fat is negatively associated with cardiovascular risk factors and does not increase the risk of a first acute myocardial infarction. A prospective case-control study. Br J Nutr 2004;91:635-42.

38. Elwood PC, Pickering JE, Hughes J, et al. Milk drinking, ischaemic heart disease and ischaemic stroke II. Evidence from cohort studies. Eur J Clin Nutr 2004;58:718-24.

39. Shah SM, Carey IM, Harris T, et al. Calcium supplementation, cardiovascular disease and mortality in older women. Pharmacoepidemiol Drug Saf 2010;19:59-64.

40. Pentti K, Tuppurainen MT, Honkanen R, et al. Use of calcium supplements and the risk of coronary heart disease in 52-62-year-old women: The Kuopio Osteoporosis Risk Factor and Prevention Study. Maturitas 2009;63:73-8.

41. Green JH, Booth C, Bunning R. Postprandial metabolic responses to milk enriched with milk calcium are different from responses to milk enriched with calcium carbonate. Asia Pac J Clin Nutr 2003;12:109-19.

42. Reid IR, Schooler BA, Hannan SF, et al. The acute biochemical effects of four proprietary calcium preparations. Aust N Z J Med 1986;16:193-7.

43. Wang TK, Bolland MJ, van Pelt NC, et al. Relationships between vascular calcification, calcium metabolism, bone density and fractures. J Bone Miner Res 2010;25:2777-85.

44. Goodman WG, Goldin J, Kuizon BD, et al. Coronary-artery calcification in young adults with end-stage renal disease who are undergoing dialysis. $N$ Engl J Med 2000;342:1478-83

45. Reid IR, Bolland MJ, Grey A. Does calcium supplementation increase cardiovascula risk? Clin Endocrinol (Oxf) 2010;73:689-95.

46. Williams DM, Fraser A, Lawlor DA. Associations of vitamin D, parathyroid hormone and calcium with cardiovascular risk factors in US adolescents. Heart 2011:97:315-20

47. Fraser A, Williams D, Lawlor DA. Associations of serum 25-hydroxyvitamin D, parathyroid hormone and calcium with cardiovascular risk factors: analysis of 3 NHANES cycles (2001-2006). PLoS One 2010;5:e13882.

48. Foley RN, Collins AJ, Ishani A et al. Calcium-phosphate levels and cardiovascular disease in community-dwelling adults: the Atherosclerosis Risk in Communities (ARIC) Study. Am Heart J 2008;156:556-63.

49. Jorde R, Sundsfjord J, Fitzgerald $P$, et al. Serum calcium and cardiovascular risk factors and diseases: the Tromso study. Hypertension 1999;34:484-90.

50. Lind L, Skarfors E, Berglund L, et al. Serum calcium: a new, independent, prospective risk factor for myocardial infarction in middle-aged men followed for 18 years. J Clin Epidemiol 1997:50:967-73.

51. Hagstrom $\mathbf{E}$, Hellman $\mathrm{P}$, Larsson $\mathrm{TE}$, et al. Plasma parathyroid hormone and the risk of cardiovascular mortality in the community. Circulation 2009;119:2765-71.

52. Kamycheva E, Sundsfjord J, Jorde R. Serum parathyroid hormone levels predict coronary heart disease: the Tromso Study. Eur J Cardiovasc Prev Rehabil 2004;11:69-74.

53. Grandi NC, Breitling LP, Hahmann $H$, et al. Serum parathyroid hormone and risk of adverse outcomes in patients with stable coronary heart disease. Heart 2011;97:1215-21.

54. Schwarzpaul S, Strassburg A, Luhrmann PM, et al. Intake of vitamin and minera supplements in an elderly german population. Ann Nutr Metab 2006:50:155-62.

55. Millen AE, Dodd KW, Subar AF. Use of vitamin, mineral, nonvitamin and nonmineral supplements in the United States: The 1987, 1992 and 2000 National Health Interview Survey results. J Am Diet Assoc 2004;104:942-50. 